$1 \quad$ Key Populations and Power: People-Centered Social Innovation in Asian HIV Services

2

3 Authors: Fan Yang ${ }^{1 \S}, \mathrm{PhD}$, Rena Janamnuaysook ${ }^{2 \S}$, MBA, Mark Boyd ${ }^{3,4}$, MD, Nittaya Phanuphak ${ }^{2}$,

$4 \quad \mathrm{PhD}$, Joseph D. Tucker ${ }^{1,5}, \mathrm{MD}$

5 Affiliations:

61 University of North Carolina at Chapel Hill, School of Medicine, Project-China, Guangzhou,

7 China

82 The Thai Red Cross AIDS Research Centre, Bangkok, Thailand

93 Faculty of Health and Medical Sciences, University of Adelaide, Adelaide, SA, Australia

4 Kirby Institute, University of New South Wales, Kensington, NSW, Australia

5 Faculty of Infectious and Tropical Diseases, London School of Hygiene and Tropical Medicine,

12 London, UK

13

**In Press at Lancet $\mathrm{HIV}^{* *}$

15

Reference: Yang D, Janamnuaysook R, Boyd M, Phanuphak N, Tucker JD. Key populations and power: People-centered social innovation in Asian HIV services. Lancet HIV. In Press.

18

19

https://www.journals.elsevier.com/the-lancet-hiv

20

$21 \bowtie$ Corresponding author: Joseph D. Tucker, MD

22

Email: jdtucker@med.unc.edu

Telephone: +447407736786 
$25 \S$ The two authors contributed equally. 


\section{Key Populations and Power: People-Centered Social Innovation in HIV Services}

27

\section{Abstract}

29 Key populations increasingly lead the design, implementation, and evaluation of HIV services. This increased power provides an opportunity to make HIV services more people-centered. Despite many challenges, there is a strong argument that key populations must play a greater role in HIV service planning, development, and delivery across the world. This viewpoint focuses on Asia where key populations have advocated for legal reform, engaged vulnerable groups to decrease stigma, cocreated innovative HIV services, and developed new key population-led health services. We use a framework of people-centered social innovation to consider the increased power of key populations to control HIV service delivery. Greater power to key populations in HIV services is demonstrated in evidence from engagement programs, co-creation activities using crowdsourcing, and key population-led health services. Further research on key populations and their roles in HIV implementation and sustainable scale-up is needed in Asia and beyond. 
41

42

In contrast to an overall decline in HIV incidence among many groups, key populations still have a high HIV incidence and unmet HIV prevention needs. ${ }^{1}$ Key populations include men who have sex with men (MSM), transgender people (TG), sex workers and their sexual partners, people who inject drugs, and incarcerated persons. Key populations are often marginalized in HIV responses in many Asian countries because of discriminatory laws, human rights violations, enduring stigma, and lack of appropriate care available in traditional service delivery approaches.

MSM accounted for $29 \%$ of new HIV infections in Asia in $2017 .{ }^{2}$ HIV prevalence among MSM in Southeast Asia was the highest in Thailand (26.2\%), Indonesia (25.8\%), Malaysia (21.6\%) and Vietnam (12.2\%). ${ }^{3}$ In China, $26 \%$ of new HIV infections occurred among MSM in $2014 .{ }^{4}$ Additionally, a few countries in Asia still criminalized same-sex sexual behaviors between consenting male adults. Punitive laws and related health communication problems have contributed to a less than $60 \%$ consistent condom use among MSM in Pakistan, Laos, Sri Lanka, and Bangladesh. ${ }^{5}$ Transgender people refer to all people whose gender identity differs from the sex they were assigned at birth. Among TG, available data indicate high HIV prevalence in many areas, including Jakarta, Indonesia (34\%), Kuala Lumpur, Malaysia (23.9\%), Cebu City, Philippines $(11 \cdot 8 \%)^{6}$ and Bangkok, Thailand $(13 \cdot 8 \%) .^{7}$ At the community level, health communication materials frequently share insensitive messages which assume TG are a subset of MSM without recognizing the specific needs of people who identify as $\mathrm{TG},{ }^{8}$ in health systems, healthcare providers can be insensitive to sexual orientation, gender identity and gender expression. ${ }^{8}$ All of these problems can translate into poor access to health services and low levels of satisfaction from clients. The HIV testing uptake rate is low among TG in many Asian countries, including the Philippines (15\%), 
Pakistan (29\%), Bangladesh (35\%), China (34\%) and Malaysia (43\%). ${ }^{7}$ Sex work is criminalized in 18 countries in Asia. ${ }^{9}$ Due to legal constraints, it remains difficult for service providers to reach sex workers and their clients. This may translate into a missed opportunity for incorporating insights from sex workers into service delivery. A low proportion of consistent condom use was found among female sex workers (FSW) in Sri Lanka, Pakistan, and Vietnam, highlighting the unmet needs for HIV prevention among FSW. ${ }^{10}$ Exacerbating the epidemic is the lack of attention given to male sex workers, among whom HIV prevalence is even higher than their female counterparts in many Asian countries. ${ }^{11}$

Despite these challenges, key populations increasingly lead the design, implementation, and evaluation of HIV services in some settings. This increased power provides an opportunity to make HIV services more people-centered. While participation can contribute to the empowerment, ${ }^{12,13}$ tokenistic engagement may inadvertently decrease power. ${ }^{14}$ This viewpoint focuses on Asia where key populations have advocated for legal reform, engaged vulnerable groups to decrease stigma, cocreated innovative health services, and developed novel key population-led health services. We selected and reviewed successful cases, consulted regional experts, and then developed a framework of people-centered social innovation to consider engagement programs, co-creation activities, and key population-led health services.

\section{People-Centered Social Innovation in HIV Services}

A people-centered approach respects peoples' dignity and the need to be respectfully treated and empowered to pursue good health and well-being. ${ }^{15,16}$ Derived from those principles, we further define a people-centered approach in HIV services as encompassing three fundamental elements. 
86 First, adopting a view to see persons as a whole, rather than mere bearers of disease or as a threat to

87 public health. This calls for a holistic examination of key populations' needs, including not only HIV and STI care and services, but also mental health, general health, and social support in the context of their dynamic interaction with the broad legal, cultural and socio-political environments. ${ }^{17}$ Second, a people-centered approach acknowledges key populations’ perspectives, experience and knowledge. Individuals with a lived personal experience of the barriers in traditional HIV programs and the facilitators of new HIV programs have a unique opportunity to take ownership of these new HIV programs. ${ }^{15,16,18}$ Thus, shifting from a disease-focused to a people-centered approach values the human experience alongside clinical evidence. ${ }^{16}$ Last, in a people-centered approach, key populations are empowered through the collaborative effort, where key populations, healthcare workers, and caregivers all contribute to the process of prevention, diagnosis and treatment. ${ }^{16}$ This contrasts the current practices in many settings where healthcare providers are the sole hegemonic authority of medical knowledge. Although people-centered approach in HIV programming shares similarities with community-based participatory research (CBPR) in its emphasis on partnership, collaboration and capacity building, the two also differ. ${ }^{19}$ A people-centered approach applies to increasing HIV-related service access and uptake among communities, without necessarily bringing in outsider researchers.

Social innovation refers to innovative activities and services carried out by organizations or groups motivated by the goal of addressing the identified needs of a community or population. ${ }^{20}$ Evidence is beginning to accumulate in the Asia where key population-centered social innovation has occurred and has already triggered promising changes in HIV programming. Extending from previous 
108 frameworks and discussions around community participation, ${ }^{21-23}$ this evidence in Asia suggests the need to systematically examine these phenomena and how they alter local power relationships.

111 We searched peer-reviewed literature and program reports related to key populations and their power

112 in the design, development, and evaluation of HIV services in Asia. We then summarized our

113 findings and presented typical cases to illustrate key populations' increased power through peoplecentered social innovation.

\section{Key Populations and Power in HIV Response in Asia}

117 The term power has been thoroughly studied across different domains of knowledge and using various theoretical lenses. ${ }^{24-26}$ Power is operationally defined as the ability to exert control over personal or community matters, in this case, the design, development, and delivery of HIV services. Increasing participation within the framework of decision making (e.g., higher levels on Arnstein's ladder of citizen participation) may give way to greater control over HIV service delivery. ${ }^{14}$

122 However, this is not always the case, as demonstrated in tokenistic participation inadvertently decreasing overall power in the control of HIV interventions. ${ }^{27}$

Greater power transferred to key populations in HIV services is demonstrated in evidence from engagement programs, co-creation activities, and key population-led health services. Engagement is defined as having key populations involved in health outreach or dissemination, but not developing the messages or leading health services. Co-creation moves one step beyond engagement and has key populations developing messages and intervention materials. Key population-led services move 130 farther than co-creation because key populations themselves lead the HIV service. In the following 
131 sections, we draw on successful examples from Asian settings to demonstrate those three ascending

132 levels of involvement from key populations in the HIV response.

Meaningful engagement of key populations in HIV services, research and programming has been pivotal and effective in many Asian settings. Key populations play important roles in outreach and mobilization among their community members who are at risk of HIV. In Thailand, the Tangerine Community Health Clinic works closely with TG social media influencers through online platforms to increase community literacy, to generate demand for HIV and related services, and to reduce internalized stigma among TG communities (See Box 1 for more details).

142 Cambodia, China, Malaysia, and Indonesia all have HIV testing programs that draw on key population staff, an acknowledgement of the potential power of key population engagement in attracting the most at-risk groups and delivering the most-needed services. In Cambodia, HIV testing services for people who inject drugs has been delivered partly through peer-led outreach. ${ }^{28}$ In China, community based organizations(CBO)-clinic hybrid service delivery is supported by MSM CBOs in collaboration with local clinical service organizations to provide HIV and syphilis testing to MSM. ${ }^{29}$ In Malaysia where same-sex relationships are illegal, a non-government organization (NGO) offered community-based voluntary HIV counseling and testing and has served more than 700 clients, among whom more than $58 \%$ disclosed same-sex sexual behaviors. ${ }^{30}$ Similarly in Indonesia, community screening sites provided a complementary entry point to HIV services among MSM

152 reluctant to seek HIV testing at government-run health facilities. ${ }^{31}$ In summary, engaging key 
153 populations in HIV interventions is able to bring services to the community and its members who are

154 otherwise marginalized by discriminatory laws and norms. With accessible HIV services and 155 resources at the community, individuals can exert increased control over their health.

157 In addition, engagement of key populations contributes to advocacy and policy formulation in Asia.

158 Together with academia, healthcare providers, multi-lateral agencies and governmental sectors,

159 representatives from TG communities and organizations in Asia participated in the development of a 160 blueprint document aiming to improve TG clinical services in this region. ${ }^{32}$ The blueprint document

161 has served as a guide for trans health and human rights in the region and was endorsed for

162 publication by the core partners, including the Asia Pacific Transgender Network, the World Health 163 Organization, the United Nations Development Programme, and the United States Agency for 164 International Development. ${ }^{32}$ In developing the blueprint document, members from the TG 165 communities representing sub-regions of Asia actively engaged in various workshops throughout a 166 year and advocated for human rights-based services for TG in HIV services. With technical 167 assistance from healthcare providers inside and outside Asia, TG community members spearheaded 168 the write-up of the blueprint document in 2015, which was unique for a regional policy statement. 169 Key population's engagement in policy formulation demonstrated control over the delivery of HIV 170 services. 


\section{Box 1. Transgender Communities' Engagement in HIV Response: A Case from Thailand}

The "Tangerine" Community Health Clinic, established in November 2015 at the Thai Red Cross AIDS Research Centre, is the first transgender health and well-being clinic in Asia, where gender-affirming hormone treatment, HIV and sexual health services are integrated as part of the comprehensive service package. Tangerine is primarily run by a trained and gender-sensitive healthcare team, where nine of the total ten staff members are transgender women (TGW). (see supplement 1 for more information on Tangerine clinic and its services).

Key population staff at the Tangerine community were all paid, full-time workers, who were empowered throughout the processes of job application, training, delivering services, and appraisal. They were formally hired and expected to delivery high-quality work.

Tangerine has monthly engaged transgender social media influencers to increase its HIV service uptake through the Tangerine Facebook page as the main online client recruitment platform. Transgender social media influencers who engaged in sex work conducted Facebook live sessions to educate their sex work communities on HIV testing and PrEP and successfully reached and recruited TGW sex workers. In addition, TGW beauty icons were able to reach out and identify young TGW and HIV first-time testers via Facebook live sessions about safe hormone use.

By the end of April 2019, there were 2,623 transgender clients receiving clinical services. Of those, 1,586 (60\%) were reached by TGW social media influencers and 1,502 (95\%) of those who were reached received HIV testing. Among this group, 390 (26\%) were first-time testers. A total of 93 (6\%) TGW had a positive HIV test result. Tangerine also harnesses the power of online TGW communities to enhance offline healthcare services. It indicates that engaging TGW in HIV responses is effective in reaching marginalized groups, improving the uptake of HIV testing, and facilitating linkage to HIV prevention and care.

\section{Co-creation of innovative HIV programs through crowdsourcing}

174 Co-creation solicits innovative ideas form the 'bottom-up', as contrasted with traditional HIV

175 services which are designed 'top-down' by policymakers. Co-creation not only facilitates that the content of social innovation reflects the lived, contextualized needs of key populations, but also empowers them to take ownership. ${ }^{33}$

179 Co-creation refers to a diverse group of individuals jointly producing a program for a mutually

180 beneficial outcome (e.g., crowdsourcing). Crowdsourcing is one example of co-creation and is 
182 sharing the solution with the public. ${ }^{34}$ Compared to traditional top-down approaches in creating 183 HIV-related communication messages, crowdsourced approaches have been shown effective in

184 generating culturally sensitive intervention messages. ${ }^{34-36}$ In China, crowdsourcing has been used to co-create interventions to promote HIV testing among MSM communities and demonstrated a 40\% increase in the probability of HIV testing over three months. ${ }^{35}$ To co-create an HIV testing 187 intervention, a 6-week nationwide open contest and a 3-day regional designathon (a hackathon-like event focusing on strategy development and material design) were organized to solicit images and intervention strategies around HIV testing tailored for MSM communities. ${ }^{35}$ This crowdsourced intervention was appraised in comparison to traditional social marketing intervention through a stepped wedge cluster randomized controlled trial in eight cities in China (see Box 2 and Supplement 2 for examples of HIV intervention content created from crowdsourcing). The effectiveness of the crowdsourced intervention suggests the potential of crowdsourcing to co-create innovative and attractive HIV interventions. The co-creation process allowed key populations greater control in the development and design of HIV services.

In addition to its use in promoting HIV testing, crowdsourcing has also been employed to solicit ideas in creating condom promotion interventions and has demonstrated similar effectiveness in reducing condomless sex when compared to social marketing messages. ${ }^{36}$ Crowdsourcing has been used to invite inputs from key populations about HIV cure research through an open contest soliciting ideas about what an HIV cure would mean to them as a person. This crowdsourcing activity provided an important voice about HIV cure research to key populations with lived experiences of HIV and HIV risk. Co-creating the meaning of HIV cure took the conversation beyond biomedical markers, viral loads, and reservoirs. Instead, it underscored the people-centered 
205 approach to deepen the scientists' understanding of what it means to live with HIV. ${ }^{37}$ A practical 206 guide on crowdsourcing in health and health research has been publicized by the 207 UNICEF/UNDP/World Bank/WHO Special Programme for Research and Training in Tropical 208 Diseases to provide a guidance for using crowdsourcing in the context of health programs. ${ }^{38}$ 209 210 
Crowdsourcing has been used in China and Thailand to solicit innovative ideas for designing culturally sensitive and effective health messages for HIV prevention and testing among MSM communities. Over the past five years, several crowdsourcing projects have been implemented by the SESH (Social Entrepreneurship to Spur Health) group in the forms of a designathon (where members from MSM communities design health messages and images for health promotion), an open contest (where contests were organized to elicit ideas openly from the public) and a hackathon (where diverse individuals create innovative technology platforms for MSM to better seek high-quality health care). One key lesson learned from the use of crowdsourcing in co-creating key population programs is to ensure that the results and the service product are shared with the community, thus closing the loop. Sharing the results could include the following activities: wide dissemination of messages through in-person and social media network; implementation of a program; organization of a pilot to evaluate efficacy; or other ways to share the finalist ideas with a broader community. Sharing typically includes both sending out these messages and telling the community how they were derived (i.e., through an iterative, community-led process). related services co-created from crowdsourcing emerge from the community and demonstrate community's power to 
Key population-led health services

229

230

231

232

233

234

235

236

237

238

239

240

241

242

243

244

245

246

247

248

249

250

251

Key populations also lead HIV-related health services in several Asian countries, including India, Thailand, and Vietnam. This approach has a key population responsible for managing, funding, designing, delivering, evaluating, and sustaining HIV services. Despite the complexity of implementing key population-led health services in certain aspects due to sociopolitical constraints, ${ }^{39-41}$ population-led health services proved to be trusted and of high quality in several studies in Asia. ${ }^{42,43}$

In Thailand, trained lay providers who were members of MSM and TGW communities demonstrated their capacity to perform finger-prick blood collection and HIV rapid diagnostic testing with excellent accuracy compared to testing conducted by medical technologists. In $2016,42 \%$ of all HIV tests among MSM and TGW in Thailand were implemented at CBOs. ${ }^{43} \mathrm{HIV}$ testing services provided by key population lay providers contributed to the diagnosis of $35 \%$ new HIV cases among MSM and TGW in the same year. ${ }^{43}$ In addition, trained key population lay providers at these CBOs have dispensed pre-exposure prophylaxis (PrEP) to at least a quarter of all PrEP users in Thailand by the end of $2017 .{ }^{44}$ Key population-led services in Thailand were largely driven by key populations who took control over types of services provided to their community and how those services were made available for the community. Services were focused on the comprehensive needs of key populations and decided by those who shared the lived experience. For example, services for male sex workers also included legal consultation and non-formal education sessions; services for transgender women included integrated feminizing hormone therapy; services were available in hotspot areas and during flexible service hours to suit living and working lifestyles; harm reduction services were added to the design based on lay providers' finding of increasing drug use among their clients. These are all bottom-up examples for key population-led health services. 
253 In Vietnam, HIV testing led by key population lay providers increased the coverage and facilitated

254 the effective diagnosis of HIV positive cases. ${ }^{45}$ HIV testing interventions led by key population lay

255 providers reached a large number of clients with an overall HIV positivity rate of $4 \cdot 1 \%$, almost three

256 times higher than the estimated HIV positivity rate from facility-based testing during the same

period (1.6\% in 2016 and $1.5 \%$ in 2017). ${ }^{45}$ Among the clients tested by the key population lay

providers, most were first-timers; half of those who tested before had not tested in the last 12

months. ${ }^{45}$ This suggests that key populations and others can play a larger role in directly delivering

260

HIV-related services.

Similarly in India, HIV-related health services led by key populations including FSW, proved

and stigma reduction through unionization and governance. ${ }^{48,49}$

\section{Box 3. Key Population-Led Health Services and Key population Governance: Avahan in India}

Avahan serves as a flagship program for key population-led health services in Asia focusing on HIV prevention for key populations including sex workers, MSM, transgender individuals, and people who inject drugs. Avahan exemplifies a comprehensive and complex large-scale project that expands across geographic areas (characterized by its coverage over six states). The projects were sustained for two terms of five years each, delivered combined interventions (ranging from community outreach, to clinical services) and were led and implemented by key population communities.

Within Avahan, the community mobilization was characterized by key population leadership. In 2004, social change agents including FSWs were identified as leaders. The social change agents led a series of services among their peers, such as advocating sex work as work, encouraging the organizing of CBOs striving for sex workers' well-being, and connecting sex workers to NGO-operated STI clinics. Avahan increased female sex worker collective identity, agency, and efficacy through enhancing the collective power of FSWs' leadership. 


\section{Challenges and Opportunities}

269 The increased power of key populations was reflected in their engagement in, co-creation of, and 270 leadership for effective HIV services across Asian countries (Table 1). The three levels of

271 involvement may build upon one another. However, the capacity of key populations to champion

272 HIV services relies on a pre-requisite enabling environment. ${ }^{39}$ Decriminalization and protective laws

273 to ensure key populations' human rights have been introduced in Thailand and some other Asian

274 countries. Same-sex sexual relationships were decriminalized in India and same sex marriage was

275 enshrined in legislation in Taiwan in 2019. Power is difficult to measure and can take various forms

276 in different settings. A supportive legal and policy environment is essential for giving key

277 populations greater power in organizing HIV services. This article draws on cases from settings

278 where local governments and policies confer a certain level of support to allow demonstrable

279 feasibility and effectiveness of key populations taking more control over the planning and delivery

280 of HIV services. These trends cannot be generalized to settings with severe legal constraints,

281 conservative cultural norms, oppression of civil society, and violation of the basic human rights of

282 key populations. At the same time, the gradual expansion of enabling environments across Asia

283 suggests that there will be more opportunities for key populations to co-create and lead health 284 services in the future.

Second, sustainable financing is critically important for key population HIV services and participation. Increasingly, funding for HIV services in Asia is shifting from foreign aid to domestic

288 funding. ${ }^{50}$ To ensure sustained services and active participation of key populations, innovative 289 financing schemes are needed to remove the persistent financial barriers to HIV service delivery. ${ }^{51}$

290 Several different financial models for supporting key population HIV services have been developed, 
291 including government, private, public-private, and social enterprise. ${ }^{51,52}$ These and other innovative 292 mechanisms can help ensure that these models are sustainable.

293

294 While empowering key populations is critical, advocacy and research should not be confined to key 295 populations alone. Altering power relationships is often slow. The fact that in certain countries key 296 population-led services have and are continuing to be accepted gives hope that further incremental 297 change is possible. As illustrated in the three levels of this people-centered social innovation 298 framework, key populations in selected settings of Asia are gaining increasing levels of control over 299 time.

300

301 In this viewpoint, we used the term 'key populations' based on the World Health Organization 302 definition. The definition is based on public health priorities and not necessarily the needs, desires, 303 and experiences of people themselves. The successful delivery of people-centered social innovation 304 in HIV care requires allies from across sectors, e.g. politicians, advocacy groups, the health system 305 as well as families, friends, and supporters of key populations. Governments should review the laws 306 and regulations to recognize the human rights of key populations and allow key populations to be at the forefront of the HIV responses. Commitment is needed to provide support and invest resources in the capacity building of key population leaders and service providers, in order to expand and support 309 rapid scale up of the key population-led health services and promote sustainable community-driven HIV responses. 
311 Table 1. People-centered social innovation in HIV services driven by giving power to key populations

\begin{tabular}{|c|c|c|}
\hline $\begin{array}{l}\text { Conventional } \\
\text { challenges }\end{array}$ & Solutions & Actions addressed by giving power to key populations \\
\hline $\begin{array}{l}\text { Service } \\
\text { delivery }\end{array}$ & $\begin{array}{l}\text { Engagement, } \\
\text { co-creation } \\
\text { and key } \\
\text { population-led } \\
\text { health } \\
\text { services }\end{array}$ & $\begin{array}{l}\text { - Utilize key population-led social media influencers to } \\
\text { identify hard-to-reach populations at high risk } \\
\text { - Apply a crowdsourcing strategy to co-create HIV } \\
\text { preventive messages to increase condom use and HIV } \\
\text { testing uptake } \\
\text { Train key population lay providers to perform certain } \\
\text { clinical HIV services such as HIV counseling and testing, } \\
\text { STI screening, PrEP and PEP dispensing, along with } \\
\text { other demand-driven services such as gender affirming } \\
\text { hormone services, legal services, and harm reduction }\end{array}$ \\
\hline $\begin{array}{l}\text { Policy and } \\
\text { regulations }\end{array}$ & Engagement & $\begin{array}{l}\text { Review policy to support financial investment for and } \\
\text { capacity building of key population-led health services } \\
\text { across the HIV cascade } \\
\text { - Advocate and participate equally with health professional } \\
\text { institutions in revising regulations to allow key } \\
\text { population to perform certain clinical HIV services } \\
\text { according to task sharing strategies }\end{array}$ \\
\hline
\end{tabular}




\begin{tabular}{|l|l|ll|}
\hline Laws on & Engagement & & Repeal laws criminalizing same-sex relationship, \\
stigma and & and co- & transgender identity and sex work \\
& $\begin{array}{l}\text { creation } \\
\text { discrimination }\end{array}$ & Organize public awareness raising campaigns to reduce \\
& stigma and discrimination towards key populations and \\
& HIV status \\
& Introduce anti-discrimination laws for key populations \\
& and provide gender sensitization for health care providers \\
& to encourage an enabling environment in healthcare \\
& settings.
\end{tabular}

313 
Table 2. Indicators for power demonstrated in the three components

\begin{tabular}{|c|c|c|c|c|}
\hline \multirow[t]{2}{*}{ Component } & \multirow{2}{*}{$\begin{array}{l}\text { Relation to } \\
\text { power }^{\S}\end{array}$} & \multicolumn{2}{|c|}{ Public Health Indicators } & \multirow[t]{2}{*}{ Explanation } \\
\hline & & Process-focused & Outcome-focused & \\
\hline Engagement & $\begin{array}{l}\text { Perceived } \\
\text { personal } \\
\text { control; } \\
\text { Learned } \\
\text { hopefulness }\end{array}$ & $\begin{array}{l}\text { Content analysis } \\
\text { that } \\
\text { demonstrates } \\
\text { that HIV-related } \\
\text { messages and } \\
\text { campaigns were } \\
\text { effectively } \\
\text { conveyed in } \\
\text { social media }\end{array}$ & $\begin{array}{l}\text { Testing and } \\
\text { preventive services } \\
\text { accessed, service } \\
\text { coverage }\end{array}$ & $\begin{array}{l}\text { Engaging in HIV } \\
\text { response includes } \\
\text { knowing status, } \\
\text { increasing awareness, } \\
\text { learning skills to } \\
\text { protect oneself from } \\
\text { diseases and illness } \\
\text { which are } \\
\text { manifestations of } \\
\text { power as it } \\
\text { demonstrates one's } \\
\text { exerting control over } \\
\text { one's own matters, in } \\
\text { this case health. }\end{array}$ \\
\hline Co-creation & $\begin{array}{l}\text { Perceived } \\
\text { community } \\
\text { control; } \\
\text { perceived } \\
\text { efficacy for } \\
\text { influencing the } \\
\text { larger system }\end{array}$ & $\begin{array}{l}\text { Key populations } \\
\text { actively design } \\
\text { HIV services, } \\
\text { construct } \\
\text { meanings, and } \\
\text { create solutions }\end{array}$ & $\begin{array}{l}\text { Control over the } \\
\text { HIV intervention } \\
\text { content and its } \\
\text { implementation }\end{array}$ & $\begin{array}{l}\text { Co-creation suggests } \\
\text { power as it } \\
\text { demonstrates the } \\
\text { community's exerting } \\
\text { control over the HIV } \\
\text { program design and its } \\
\text { content. Key } \\
\text { population } \\
\text { communities through } \\
\text { co-creation are able to } \\
\text { influence the larger } \\
\text { system. }\end{array}$ \\
\hline $\begin{array}{l}\text { Governance/ } \\
\text { KPLHS }\end{array}$ & $\begin{array}{l}\text { Holding } \\
\text { leadership } \\
\text { positions at } \\
\text { community } \\
\text { organizations } \\
\text { and activities }\end{array}$ & $\begin{array}{l}\text { Key populations } \\
\text { have } \\
\text { opportunities } \\
\text { and priority to } \\
\text { lead HIV } \\
\text { services and } \\
\text { grow through } \\
\text { capacity } \\
\text { building and } \\
\text { mentorship }\end{array}$ & $\begin{array}{l}\text { HIV services are } \\
\text { led by key } \\
\text { populations } \\
\text { themselves, who } \\
\text { take control over } \\
\text { the hiring process, } \\
\text { finances, training, } \\
\text { and service } \\
\text { operation. }\end{array}$ & $\begin{array}{l}\text { Key population have } \\
\text { control over decision } \\
\text { making and assume } \\
\text { leadership roles, which } \\
\text { demonstrates their } \\
\text { control. }\end{array}$ \\
\hline
\end{tabular}

$\S$ Concepts adapted from the literature on control, power, and authority in public health. ${ }^{27,53-55}$ 


\section{Acknowledgement}

318 The authors would like to thank India HIV/AIDS Alliance for providing images of the Avahan

319 Project. The authors also thank colleagues from the Thai Red Cross Research Centre, the Tangerine 320 Clinic, and Social Entrepreneurship to Spur Health (SESH) study group for providing information

321 and multimedia resources. We would also like to thank the TDR Social Innovation in Health

322 Initiative. This research was supported by the NIH (UG3HD096929 and NIAID K24AI143471).

324 Author Contributions

325 JDT conceptualized this manuscript. FY and RJ carried out literature review, acquired the data, and 326 co-wrote the first draft of the manuscript with inputs from JDT, MB and NP. JDT, MB and NP

327 provided critical revisions and essential references. All authors read and approved the final version 328 that was submitted.

\section{Declarations of Interest}

331 Dr. Boyd reports grants and personal fees from Gilead, personal fees from ViiV Healthcare, grants 332 from Merck \& Co., personal fees from Mylan, outside the submitted work. The authors declare no 333 other interests. 
1. UNAIDS. Global AIDS update 2018: Miles to go-closing gaps, breaking barriers, righting injustices. Joint United Nations Programme on HIV/AIDS (UNAIDS) Geneva; 2018. Available at: https://www.unaids.org/en/resources/documents/2018/global-aids-update (Accessed 26 July 2019) 2. State of the epidemic: UNAIDS 2018. Geneva, Switzerland. Available at: https://www.unaids.org/sites/default/files/media_asset/unaids-data-2018_en.pdf (Accessed 26 July 2019)

3. HIV prevalence in men who have sex with men. HIV and AIDS Data Hub for Asia Pacific;

2017. Available at: https://www.aidsdatahub.org/ (Accessed 26 July 2019)

4. UNAIDS. 2015 China AIDS response progress report. Ministry of Health of the People's

Republic of China Beijing; 2015. Available at: https://www.unaids.org/sites/default/files/country/documents/CHN_narrative_report_2015.pdf (Accessed 26 July 2019)

347 5. Condom use among men who have sex with men. HIV and AIDS Data Hub for Asia Pacific; 2015-2017. Available at: https://www.aidsdatahub.org/ (Accessed 26 July 2019) in Ho Chi Minh City, Vietnam. AIDS and Behavior 2016; 20(Suppl 3): 379-85.

7. United Nations Human Rights Office of the High Commissioner. Transgender People. Available at: https://aidsdatahub.org/sites/default/files/publication/UNFE_Transgender_Factsheet_2019.pdf (Accessed 26 July 2019)

8. Janamnuaysook R, Kongkapan J, et al. Transgender-Led Social Media Interventions Effectively Identify Transgender Woman Subpopulations at Substantial Risk of HIV Acquisition and Successfully Link to HIV Prevention, Care, and Treatment Services. International AIDS Society Conference July $24^{\text {th }}$, 2019. Mexico City: 2019.

9. UNAIDS, UNODC, UNFPA, UNDP. Punitive Laws Hindering the HIV Response in Asia and the Pacific (October 2014). 2014. Available at: https://hivlawcommission.org/wpcontent/uploads/2017/06/UNAIDS-Punitive-Laws-poster-v34-5.pdf (Accessed 26 July 2019) 10. HIV and AIDS Data Hub for Asia Pacific. Female Sex Workers. Powerpoint slide deck. Available at: https://www.aidsdatahub.org/female-sex-workers-2018-slides (Accessed 26 July 2019). 11. HIV and AIDS Data Hub for Asia Pacific. Male Sex Workers. Powerpoint slide deck. Available at: https://www.aidsdatahub.org/male-sex-workers-2018 (Accessed 26 July 2019). 12. Schulz AJ, Israel BA, Zimmerman MA, Checkoway BN. Empowerment as a multi-level construct: perceived control at the individual, organizational and community levels. Health Education Research 1995; 10(3): 309-27.

13. Zimmerman MA. Toward a theory of learned hopefulness: A structural model analysis of participation and empowerment. Journal of Research in Personality 1990; 24(1): 71-86.

14. Arnstein SR. A ladder of citizen participation. Journal of the American Institute of Planners 1969; 35(4): 216-24.

15. Cloninger CR, Salvador-Carulla L, Kirmayer LJ, et al. A Time for Action on Health Inequities: Foundations of the 2014 Geneva Declaration on Person- and People-centered Integrated Health Care for All. International Journal of Person Centered Medicine 2014; 4(2): 69-89. 16. Mezzich JE, Salloum IM, Cloninger CR, et al. Person-centred integrative diagnosis: conceptual bases and structural model. Canadian Journal of Psychiatry 2010; 55(11): 701-8. 
17. Ozer EJ. Youth-Led Participatory Action Research: Developmental and Equity Perspectives. Adv Child Dev Behav 2016; 50: 189-207.

18. Salvador-Carulla L, Cloninger CR, Thornicroft A, Mezzich JE. Background, Structure and Priorities of the 2013 Geneva Declaration on Person-centered Health Research. International Journal of Person Centered Medicine 2013; 3(2): 109-13. assessing partnership approaches to improve public health. Annual Review of Public Health 1998; 19(1): 173-202.

20. Mulgan G, Tucker S, Ali R, Sanders B. Social innovation: what it is, why it matters and how it can be accelerated. 2007.Oxford, UK. Skoll Centre for Social Entrepreneurship.

21. Draper AK, Hewitt G, Rifkin S. Chasing the dragon: developing indicators for the assessment of community participation in health programmes. Social Science \& Medicine 2010; 71(6): 1102-9.

22. Cornwall A. Unpacking 'Participation': models, meanings and practices. Community Development Journal 2008; 43(3): 269-83. constrained countries: a scoping review. Health Promotion International 2017; 33(4): 723-33. 24. Wojcicki JM, Malala J. Condom use, power and HIV/AIDS risk: sex-workers bargain for survival in Hillbrow/Joubert Park/Berea, Johannesburg. Social Science \& Medicine (1982) 2001; 53(1): 99-121.

25. Wingood GM, Scd, DiClemente RJ. Application of the theory of gender and power to examine HIV-related exposures, risk factors, and effective interventions for women. Health Education \& Behavior 2000; 27(5): 539-65.

26. Cooper JE, Dow WH, de Walque D, et al. Female sex workers use power over their day-today lives to meet the condition of a conditional cash transfer intervention to incentivize safe sex. Social Science \& Medicine (1982) 2017; 181: 148-57.

27. McLaughlin K. Empowerment : a critique. New York, NY: Routledge; 2016.

28. Mburu G, Ngin C, Tuot S, Chhoun P, Pal K, Yi S. Patterns of HIV testing, drug use, and sexual behaviors in people who use drugs: findings from a community-based outreach program in Phnom Penh, Cambodia. Addiction Science \& Clinical Practice 2017; 12(1): 27.

29. Tucker JD, Muessig KE, Cui R, et al. Organizational characteristics of HIV/syphilis testing services for men who have sex with men in South China: a social entrepreneurship analysis and implications for creating sustainable service models. BMC Infect Dis 2014; 14: 601.

30. Koh KC, Yong LS. HIV Risk Perception, Sexual Behavior, and HIV Prevalence among Men-Who-Have-Sex-with-Men at a Community-Based Voluntary Counseling and Testing Center in Kuala Lumpur, Malaysia. Interdiscip Perspect Infect Dis 2014; 2014: 236240.

31. Hidayat R, Marguari D, Hairunisa N, Suparno H, Magnani R. Community HIV Screening among MSM in Three Indonesian Cities. Current HIV Research 2019.

32. UNDP. Blueprint for the provision of comprehensive care for trans people and trans communities in Asia and the Pacific. 2015. Available at: http://www.asiapacific.undp.org/content/rbap/en/home/library/democratic_governance/hiv_aids/blueprint-for-theprovision-of-comprehensive-care-for-trans-peop.html (Accessed 26 July 2019)

33. Brizay U, Golob L, Globerman J, et al. Community-academic partnerships in HIV-related research: a systematic literature review of theory and practice. Journal of the International AIDS Society 2015; 18(1): 19354. 
34. Tucker JD, Day S, Tang W, Bayus B. Crowdsourcing in medical research: concepts and applications. PeerJ 2019; 7: e6762.

35. Tang W, Wei C, Cao B, et al. Crowdsourcing to expand HIV testing among men who have sex with men in China: A closed cohort stepped wedge cluster randomized controlled trial. PLoS Med 2018; 15(8): e1002645.

36. Tang W, Mao J, Liu C, et al. Reimagining Health Communication: A Non-Inferiority Randomized Controlled Trial of Crowdsourced intervention in China. Sex Transm Dis 2018; 46:172178.

37. Zhang A, Pan X, Wu F, et al. What Would an HIV Cure Mean to You? Qualitative Analysis from a Crowdsourcing Contest in Guangzhou, China. AIDS Research and Human Retroviruses 2018; 34(1): 80-7.

38. World Health Organization \& UNICEF/UNDP/World Bank/WHO Special Programme for Research and Training in Tropical Diseases. Crowdsourcing in health and health research: a practical guide: World Health Organization, 2018. Available at:

https://apps.who.int/iris/handle/10665/273039 (Accessed 26 July 2019)

39. Cornish F, Campbell C, Shukla A, Banerji R. From brothel to boardroom: Prospects for community leadership of HIV interventions in the context of global funding practices. Health \& Place 2012; 18(3): 468-74.

40. Cornish F, Shukla A, Banerji R. Persuading, protesting and exchanging favours: strategies used by Indian sex workers to win local support for their HIV prevention programmes. AIDS Care 2010; 22(sup2): 1670-8.

41. Evans C, Lambert H. Implementing community interventions for HIV prevention: insights from project ethnography. Social Science \& Medicine 2008; 66(2): 467-78.

42. Green KE, Vu BN, Phan HT, et al. From conventional to disruptive: upturning the HIV testing status quo among men who have sex with men in Vietnam. Journal of the International AIDS Society 2018; 21: e25127.

43. Wongkanya $\mathrm{R}$, Pankam $\mathrm{T}$, Wolf $\mathrm{S}$, et al. HIV rapid diagnostic testing by lay providers in a key population-led health service programme in Thailand. Journal of Virus Eradication 2018; 4(1): 12.

44. Phanuphak N, Sungsing T, Jantarapakde J, et al. Princess PrEP program: the first key population-led model to deliver pre-exposure prophylaxis to key populations by key populations in Thailand. Sexual health 2018; 15(6): 542-55.

45. Vu BN, Green KE, Phan HTT, et al. Lay provider HIV testing: A promising strategy to reach the undiagnosed key populations in Vietnam. PloS One 2018; 13(12): e0210063.

46. Galavotti C, Wheeler T, Kuhlmann AS, et al. Navigating the swampy lowland: a framework for evaluating the effect of community mobilisation in female sex workers in Avahan, the India AIDS Initiative. J Epidemiol Community Health 2012: jech-2011-200465.

47. Blankenship KM, West BS, Kershaw TS, Biradavolu MR. Power, community mobilization, and condom use practices among female sex workers in Andhra Pradesh, India. AIDS 2008; 22: S109-S16.

48. Fehrenbacher AE, Chowdhury D, Ghose T, Swendeman D. Consistent Condom Use by Female Sex Workers in Kolkata, India: Testing Theories of Economic Insecurity, Behavior Change, Life Course Vulnerability and Empowerment. AIDS and Behavior 2016; 20 (10): 2332-45.

49. Ghose T, Swendeman D, George S, Chowdhury D. Mobilizing collective identity to reduce HIV risk among sex workers in Sonagachi, India: the boundaries, consciousness, negotiation framework. Social Science \& Medicine (1982) 2008; 67(2): 311-20. 
469 50. Stuart RM, Lief E, Donald B, Wilson D, Wilson DP. The funding landscape for HIV in Asia 470 and the Pacific. Journal of the International AIDS Society 2015; 18(1): 20004.

471 51. Tucker JD, Fenton KA, Peckham R, Peeling RW. Social entrepreneurship for sexual health 472 (SESH): a new approach for enabling delivery of sexual health services among most-at-risk 473 populations. PLoS Med 2012; 9(7): e1001266.

474 52. Colby D, Srithanaviboonchai K, Vanichseni S, et al. HIV pre-exposure prophylaxis and 475 health and community systems in the Global South: Thailand case study. Journal of the 476 International AIDS Society 2015; 18(4 Suppl 3): 19953.

477 53. Israel BA, Checkoway B, Schulz A, Zimmerman M. Health education and community 478 empowerment: conceptualizing and measuring perceptions of individual, organizational, and 479 community control. Health Educ Q 1994; 21(2): 149-70.

480 54. Rappaport J. Terms of empowerment/exemplars of prevention: toward a theory for 481 community psychology. Am J Community Psychol 1987; 15(2): 121-48.

482 55. Zimmerman M. Toward a Theory of Learned Hopefulness: A Structural Model Analysis of 483 Participation and Empowerment. Journal of Research in Personality 1990; 24: 71-86. 
485 Supplement 1. Tangerine community health clinic:

486 https://www.youtube.com/watch?v=8KjCjLGau18

487 Supplement 2. HIV testing promotion video developed through a co-creation approach:

488 https://youtu.be/WbDpNrV3avg 